\title{
On an Attempt to Explore the Possible Challenges Faced by Upcoming and Established Photography Content Writers in India
}

\author{
Yogender Singh \\ Aryabhatt College, \\ University of Delhi, \\ Delhi, India
}

\author{
Lakshay Aggarwal \\ Recventures Education Services \\ Private Limited \\ Delhi, India
}

\author{
Remica Aggarwal \\ Recventures Education Services \\ Private Limited \\ Delhi, India
}

\begin{abstract}
Photography is an art derived from the principles of science. Precisely it is a derivation from the science of optics. This discipline of art requires a set of perfectly written words to be enhanced to its fullest extent .Content writing in photography is such a phenomenon. Present paper focuses on various challenges faced while doing content writing in photography. Further, it tries to establish the inter-relationships amongst them using ISM methodology .
\end{abstract}

\section{Keywords}

Content writing; ISM Methodology

\section{INTRODUCTION}

Words generally can't do a thing which a picture can. This is truly valid since history, however an imaginative graphic design blogger knows that it is so difficult to put his plan in words. As a matter of fact, the achievement of the visual computerization business generally relies upon the inventiveness, regardless of whether it is a plan or a blog post. In any case, frequently picture takers and visual originators battle to discover new motivation for articles for their outlines.

Present research focuses on first exploring various challenges associated with content writing in photography . thereafter it trues to establish the relationship amongst them using ISM methodology.

The paper is arranged as follows :Section 2 deals with various challenges associated with content writing and content writing in photography in particular with reference to developing countries like India It further tries to explore the relationship amongst them using ISM methodology in section 4 .Section 5 provides the conclusions and managerial recommendations.

\section{LITERATURE REVIEW [ 1-3]}

1. Poor activity in website community [PAWC] : It is very necessary for the graphic designers to be active in various graphic design communities. This will help them in getting ideas on various topics related to photography and graphic design blogging and also about the current trend. They are also a medium of checking the writings of famous bloggers and share views and attitudes with them. There are many community sites where as a writer, you can find writing inspiration. For easy understanding of the community sites, you can divide into two groups- Marketplace and Social Media. however, poor activity in website communities do create a barrier in professional growth of photography content writers.
2. Poor activity in online market places [PAOMP] : There are millions of graphic designers and photographers who are selling their products on various online marketplaces. These great personnel are displaying their designs and photographs in these marketplaces where you will get ample writing inspiration from. some of the popular online market places are Behance , Graphic river, 99 design, Divine tart etc.

3. Poor activity on social media [PASM]: There are numerous person to person networking sites where you can get motivation of blog compositions. There are many comprehensively perceived graphic designers and photographers who have opened records on these destinations to get required with the fan-devotees and talk with them. Consistently they post their most recent works for open surveys. Poor activity on social media sites is a major barrier.

4. Lack of challenging issues from others [LCI]: As a writer, you should have communication with the other contemporary writers on design and photography. However, you can communicate with the professional graphic designer and the photographers and get their ideas and concepts about the trend, design or photography style,etc., challenges they face during working on graphic design, photography, necessary instruments, their prospect, their future plan, etc. Lack of such challenging issues act as a major barrier .

5. Weak or inactive FAQ maintenance [WIQM] on website : We like to recommend you to keep an active FAQ option in your website. Try to update and add new questions and answers regularly. Try to give an exact answer of the question and there must have useful direction. From this option, your traffic will get most of their necessary queries solved. And if there are further questions, they will ask through the 'ask me anything form'. In this way, you can have content creating inspiration.

6. Weak response to past Emails and Social Media Interactions [WRESMI] : In the past, you might have exchanged many emails with your clients. There might have many queries from your clients and you might answer for those questions. The same thing may happen in case of social media messaging. During the conversation and in boxing with your clients, there is a possibility to be discussed a lot of issues on photography and graphic design. 
7. Inability or inappropriateness of exact Keywords [IEK]: For generating content writing inspiration, keyword research can play a very vital role. You can take this advantage to have your content ideas. In the search result, you can get many unique keywords. If you study a little, you must get a lot of blog content writing inspirations.

8. Inability to be yourself [IBY] : What is most importantly required in photography content writing is getting to the heart of what you want to say about your photos, especially if you would like people to hire you. These basic principles hold true in all sorts of photography writing contexts. What sort of problem are you solving with your photography blog? Perhaps your readers are new to photography and your writing offers a window into the photographer's life. however weak exposure and content writing badly influence the self - esteem .

9. Lack of Clarity of Growth Pattern (LOC)/ lack of career growth [LCG]: Organizations should bring out a growth plan for content writers particularly in photography. This will lead to an increase in the desirability of content writing profession, ultimately leading the business to the path of growth and prosperity.

10. Lack of Societal Awareness and Acceptance (LSA): The society should understand that if writing is a passion for someone, they should not discard the one pursuing it. Parents should encourage their children if they want to go into this profession passionately. Content writing particularly in photography is still emerging in India, but it has great potential if right people come into it.

11. Lack of sources of Information (LSI): Content writing is a profound accountability, and thus the writers need to make a lot of efforts in research. Companies in developed countries have central resources to get correct facts for research, and thus it makes it an easy job for writers there. In India, companies desire everything right from scratch from the writers only, which at times, makes them run out of interest in this field.

12. High Attrition, Low Quality (HA/LQ): As the majority of the online work is done through freelance clients connected globally through the internet, the attrition rate is very high. You may even encounter many hoax clients and might not earn even a single penny for your hard work. Professionally educated people generally don't prefer to join content writing industry. Therefore, it's rare to find a high-quality writer in this field in India.

\section{INTERPRETIVE STRUCTURAL MODELLING METHODOLOGY}

Interpretive structural modelling methodology or ISM [4] is a known technique to map the relationships amongst the relevant elements as per decision maker's problems in a hierarchical manner. Starting with the identification of elements, it proceeds with establishing the contextual relationships between elements (by examining them in pairs ) and move on towards developing the structural selfinteraction (SSIM) matrix using VAXO [21] and then initial reachability matrix and final reachability matrix and rearranging the elements in topological order using the level partition matrices. A Mic-Mac analysis is performed afterwards which categorize the variables as per the driving and dependence power in to autonomous, dependent, driver and linkage category. Finally, a diagraph can be obtained.

\section{DEVELOPMENT OF ISM MODEL : CASE EXAMPLE}

The 12 barriers viz. Poor activity in website community [PAWC]; Poor activity in online market places [PAOMP]; Poor activity on social media [PASM]; Lack of challenging issues from others [LCI] ; Weak or inactive FAQ maintenance [WIQM] on website ; Weak response to past Emails and Social Media Interactions [WRESMI]; Inability or inappropriateness of exact keyword [IEK] ; Inability to be yourself [IBY] ; Lack of clarity of growth pattern [LCGP] ; Lack of societal awareness and acceptance [LSAA]; Lack of sources of information [LSI] ; High attrition and low quality [HA/LQ] described in section 2 above have been studied further for the possible inter-relationship amongst them using ISM methodology .

\subsection{Construction of Structural self- interaction Matrix (SSIM)}

This matrix gives the pair-wise relationship between two variables i.e. I and $j$ based on VAXO. SSIM has been presented below in Fig 1.

\subsection{Construction of Initial Reachability \\ Matrix and final reachability matrix}

The SSIM has been converted in to a binary matrix called the initial reachability matrix shown in fig. 2 by substituting V, A, $\mathrm{X}, \mathrm{O}$ by 1 or 0 as per the case. After incorporating the transitivity, the final reachability matrix is shown below in the Fig

\begin{tabular}{|c|c|c|c|c|c|c|c|c|c|c|c|c|c|}
\hline S. No. & Barriers & 1 & 2 & 3 & 4 & 5 & 6 & 7 & 8 & 9 & 10 & 11 & 12 \\
\hline & & PAWC & PAOMP & PASM & LCI & WIQM & $\begin{array}{c}\text { WRE } \\
\text { SMI }\end{array}$ & IEK & IBY & LCGP & $\begin{array}{c}\text { LSAA } \\
\text { LSI }\end{array}$ & $\begin{array}{c}\text { HA/L } \\
\text { Q }\end{array}$ \\
\hline 1 & PAWC & & $\mathrm{X}$ & $\mathrm{X}$ & $\mathrm{X}$ & $\mathrm{X}$ & $\mathrm{X}$ & $\mathrm{X}$ & $\mathrm{X}$ & $\mathrm{X}$ & $\mathrm{X}$ & $\mathrm{X}$ & $\mathrm{V}$ \\
\hline 2 & PAOMP & & & $\mathrm{X}$ & $\mathrm{A}$ & $\mathrm{X}$ & $\mathrm{X}$ & $\mathrm{A}$ & $\mathrm{V}$ & $\mathrm{V}$ & $\mathrm{V}$ & $\mathrm{V}$ & $\mathrm{V}$ \\
\hline 3 & PASM & & & & $\mathrm{V}$ & $\mathrm{V}$ & $\mathrm{V}$ & $\mathrm{V}$ & $\mathrm{V}$ & $\mathrm{V}$ & $\mathrm{V}$ & $\mathrm{V}$ & $\mathrm{V}$ \\
\hline 4 & LCI & & & & & $\mathrm{V}$ & $\mathrm{V}$ & $\mathrm{V}$ & $\mathrm{V}$ & $\mathrm{V}$ & $\mathrm{V}$ & $\mathrm{V}$ & $\mathrm{V}$ \\
\hline 5 & WIQM & & & & & & $\mathrm{V}$ & $\mathrm{O}$ & $\mathrm{V}$ & $\mathrm{V}$ & $\mathrm{V}$ & $\mathrm{V}$ & $\mathrm{V}$ \\
\hline 6 & WRESMI & & & & & & & $\mathrm{O}$ & $\mathrm{V}$ & $\mathrm{A}$ & $\mathrm{A}$ & $\mathrm{V}$ & $\mathrm{V}$ \\
\hline 7 & IEK & & & & & & & & $\mathrm{V}$ & $\mathrm{V}$ & $\mathrm{V}$ & $\mathrm{V}$ & $\mathrm{V}$ \\
\hline 8 & IBY & & & & & & & & & $\mathrm{A}$ & $\mathrm{A}$ & $\mathrm{A}$ & $\mathrm{A}$ \\
\hline
\end{tabular}




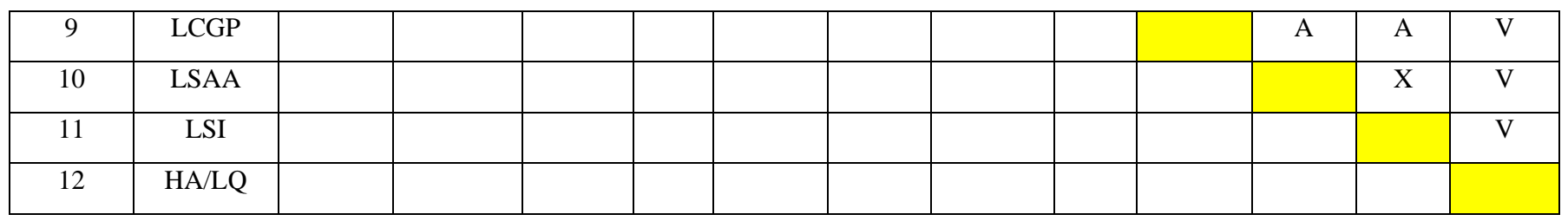

Fig 1: SSIM matrix for pair wise relationship amongst barriers

\begin{tabular}{|c|c|c|c|c|c|c|c|c|c|c|c|c|c|}
\hline S. No. & Barriers & 1 & 2 & 3 & 4 & 5 & 6 & 7 & 8 & 9 & 10 & 11 & 12 \\
\hline & & PAWC & PAOMP & PASM & LCI & WIQM & $\begin{array}{c}\text { WRE } \\
\text { SMI }\end{array}$ & IEK & IBY & $\begin{array}{c}\text { LCGP } \\
\text { LSAA }\end{array}$ & $\begin{array}{c}\text { LSI } \\
\text { HA/L } \\
\text { Q }\end{array}$ \\
\hline 1 & PAWC & 1 & 1 & 1 & 1 & 1 & 1 & 1 & 1 & 1 & 1 & 1 & 1 \\
\hline 2 & PAOMP & 1 & 1 & 1 & 0 & 1 & 1 & 0 & 1 & 1 & 1 & 1 & 1 \\
\hline 3 & PASM & 1 & 1 & 1 & 1 & 1 & 1 & 1 & 1 & 1 & 1 & 1 & 1 \\
\hline 4 & LCI & 1 & 1 & 0 & 1 & 1 & 1 & 1 & 1 & 1 & 1 & 1 & 1 \\
\hline 5 & WIQM & 1 & 1 & 0 & 0 & 1 & 1 & 0 & 1 & 1 & 1 & 1 & 1 \\
\hline 6 & WRESMI & 1 & 1 & 0 & 0 & 0 & 1 & 0 & 1 & 0 & 0 & 1 & 1 \\
\hline 7 & IEK & 1 & 1 & 0 & 0 & 0 & 0 & 1 & 1 & 1 & 1 & 1 & 1 \\
\hline 8 & IBY & 1 & 0 & 0 & 0 & 0 & 0 & 0 & 1 & 0 & 0 & 0 & 0 \\
\hline 9 & LCGP & 1 & 0 & 0 & 0 & 0 & 1 & 0 & 1 & 1 & 0 & 0 & 1 \\
\hline 10 & LSAA & 1 & 0 & 0 & 0 & 0 & 1 & 0 & 1 & 1 & 1 & 1 & 1 \\
\hline 11 & LSI & 1 & 0 & 0 & 0 & 0 & 0 & 0 & 1 & 1 & 1 & 1 & 1 \\
\hline 12 & HA/LQ & 0 & 0 & 0 & 0 & 0 & 0 & 0 & 1 & 0 & 0 & 0 & 1 \\
\hline
\end{tabular}

Fig 2: Initial reachability matrix

\begin{tabular}{|c|c|c|c|c|c|c|c|c|c|c|c|c|c|c|}
\hline S. No. & Barriers & 1 & 2 & 3 & 4 & 5 & 6 & 7 & 8 & 9 & 10 & 11 & 12 & D.P \\
\hline & & PAWC & PAOMP & PASM & LCI & WIQM & $\begin{array}{c}\text { WRE } \\
\text { SMI }\end{array}$ & IEK & IBY & LCGP & $\begin{array}{c}\text { LSAA } \\
\text { LSI }\end{array}$ & $\begin{array}{c}\text { HA/L } \\
\text { Q }\end{array}$ & \\
\hline 1 & PAWC & 1 & 1 & 1 & 1 & 1 & 1 & 1 & 1 & 1 & 1 & 1 & 1 & 12 \\
\hline 2 & PAOMP & 1 & 1 & 1 & 1 & 1 & 1 & 1 & 1 & 1 & 1 & 1 & 1 & 12 \\
\hline 3 & PASM & 1 & 1 & 1 & 1 & 1 & 1 & 1 & 1 & 1 & 1 & 1 & 1 & 12 \\
\hline 4 & LCI & 1 & 1 & 1 & 1 & 1 & 1 & 1 & 1 & 1 & 1 & 1 & 1 & 12 \\
\hline 5 & WIQM & 1 & 1 & 1 & 0 & 1 & 1 & 1 & 1 & 1 & 1 & 1 & 1 & 11 \\
\hline 6 & WRESMI & 1 & 1 & 1 & 0 & 1 & 1 & 0 & 1 & 1 & 1 & 1 & 1 & 1 \\
\hline 7 & IEK & 1 & 1 & 1 & 1 & 1 & 1 & 1 & 1 & 1 & 1 & 1 & 1 & 12 \\
\hline 8 & IBY & 1 & 1 & 1 & 1 & 1 & 1 & 1 & 1 & 1 & 1 & 1 & 1 & 12 \\
\hline 9 & LCGP & 1 & 1 & 1 & 1 & 1 & 1 & 1 & 1 & 1 & 1 & 1 & 1 & 12 \\
\hline 10 & LSAA & 1 & 1 & 1 & 1 & 1 & 1 & 1 & 1 & 1 & 1 & 1 & 1 & 12 \\
\hline 11 & LSI & 1 & 0 & 0 & 0 & 0 & 1 & 0 & 1 & 1 & 1 & 1 & 1 & 7 \\
\hline 12 & HA/LQ & 1 & 0 & 0 & 0 & 0 & 0 & 0 & 1 & 0 & 0 & 0 & 1 & 3 \\
\hline & De.P & 12 & 10 & 10 & 8 & 10 & 11 & 9 & 12 & 11 & 11 & 11 & 12 & \\
\hline
\end{tabular}

\section{Fig 3 : Final reachability matrix}

\section{LEVEL PARTITION}

From the final reachability matrix, reachability and final antecedent set for each factor are found. The element for which the reachability and intersection sets are same are the top-level element in the ISM hierarchy. After the identification of top level element, it is separated out from the other elements and the process continues for next level of elements. Reachability set, antecedent set, intersection set along with different level for elements have been shown below in table 1 to table 4 . 
Table 1 : Iteration I

\begin{tabular}{|c|c|c|c|c|}
\hline $\begin{array}{l}\text { S. } \\
\text { no }\end{array}$ & $\begin{array}{c}\text { Reachability } \\
\text { set }\end{array}$ & $\begin{array}{l}\text { Antecedent } \\
\text { set }\end{array}$ & $\begin{array}{l}\text { Intersecti } \\
\text { on set }\end{array}$ & $\begin{array}{c}\text { Level } \\
\text { / } \\
\text { iterat } \\
\text { ion }\end{array}$ \\
\hline 1. & $1,8,12$ & $\begin{array}{c}1,2,3,4,5,6,7,8 \\
9,10,11 \\
12\end{array}$ & $1,8,12$ & \\
\hline 2. & $\begin{array}{c}1,6,8,9,10,11,1 \\
2\end{array}$ & $\begin{array}{c}1,2,3,4,5,6,7,8 \\
9,10,11\end{array}$ & $\begin{array}{c}1,6,8,9,10 \\
, 11\end{array}$ & I \\
\hline 3. & $\begin{array}{c}1,2,3,5,6,8,9,1 \\
0,11,12\end{array}$ & $\begin{array}{c}1,2,3,4,5,6,7,8 \\
9,10\end{array}$ & $\begin{array}{c}1,2,3,5,6 \\
8,9,10\end{array}$ & \\
\hline 4. & $\begin{array}{c}1,2,3,5,6,7,8,9 \\
10,11,12\end{array}$ & $\begin{array}{c}1,2,3,4,5,7,8,9 \\
10\end{array}$ & $\begin{array}{c}1,2,3,5,7, \\
8,9,10\end{array}$ & \\
\hline 5. & $\begin{array}{c}1,2,3,4,5,6,7,8 \\
9,10,11,12\end{array}$ & $1,2,3,4,7,8,9$ & $\begin{array}{c}1,2,3,4,7 \\
8,9\end{array}$ & \\
\hline
\end{tabular}

Table 2 : Iteration II

\begin{tabular}{|c|c|c|c|c|}
\hline $\begin{array}{c}\text { S.n } \\
\text { o }\end{array}$ & $\begin{array}{c}\text { Reachability } \\
\text { set }\end{array}$ & Antecedent set & $\begin{array}{c}\text { Intersecti } \\
\text { on set }\end{array}$ & $\begin{array}{c}\text { Lev } \\
\text { el }\end{array}$ \\
\hline 2. & $6,9,10,11$ & $\begin{array}{c}2,3,4,5,6,7,9,10 \\
, 11\end{array}$ & $6,9,10,11$ & \multirow{4}{*}{ I } \\
\hline 3. & $2,3,5,6,9,10,11$ & $2,3,4,5,6,7,9,10$ & $\begin{array}{c}2,3,5,6,9,1 \\
0\end{array}$ & \\
\hline 4. & $\begin{array}{c}2,3,5,6,7,9,10,1 \\
1\end{array}$ & $2,3,4,5,7,9,10$ & $\begin{array}{c}2,3,5,7,9,1 \\
0\end{array}$ & \\
\hline 5. & $\begin{array}{c}2,3,4,5,6,7,9,10 \\
, 11\end{array}$ & $2,3,4,7,9$ & $2,3,4,7,9$ & \\
\hline
\end{tabular}

Table 3: Iteration III

\begin{tabular}{|c|c|c|c|c|}
\hline s.no & $\begin{array}{c}\text { Reachability } \\
\text { set }\end{array}$ & $\begin{array}{c}\text { Antecedent } \\
\text { set }\end{array}$ & $\begin{array}{c}\text { Intersection } \\
\text { set }\end{array}$ & Level \\
\cline { 1 - 4 } $\mathbf{3 .}$ & $2,3,5$ & $2,3,4,5,7$ & $2,3,5$ & \\
\cline { 1 - 3 } $\mathbf{4 .}$ & $\mathbf{2 , 3 , 5 , 7}$ & $2,3,4,5,7$ & $2,3,5,7$ & \multirow{2}{*}{ III } \\
\cline { 1 - 3 } $\mathbf{5 .}$ & $2,3,4,5,7$ & $2,3,4,7$ & $2,3,4,7$ & \\
\hline
\end{tabular}

Table 4: Iteration IV

\begin{tabular}{|c|c|c|c|c|}
\hline s.no & $\begin{array}{c}\text { Reachability } \\
\text { set }\end{array}$ & $\begin{array}{c}\text { Antecedent } \\
\text { set }\end{array}$ & $\begin{array}{c}\text { Intersection } \\
\text { set }\end{array}$ & Level \\
\hline $\mathbf{5 .}$ & $\mathbf{4}$ & 4 & 4 & IV \\
\hline
\end{tabular}

\section{ISM DIAGRAPH}

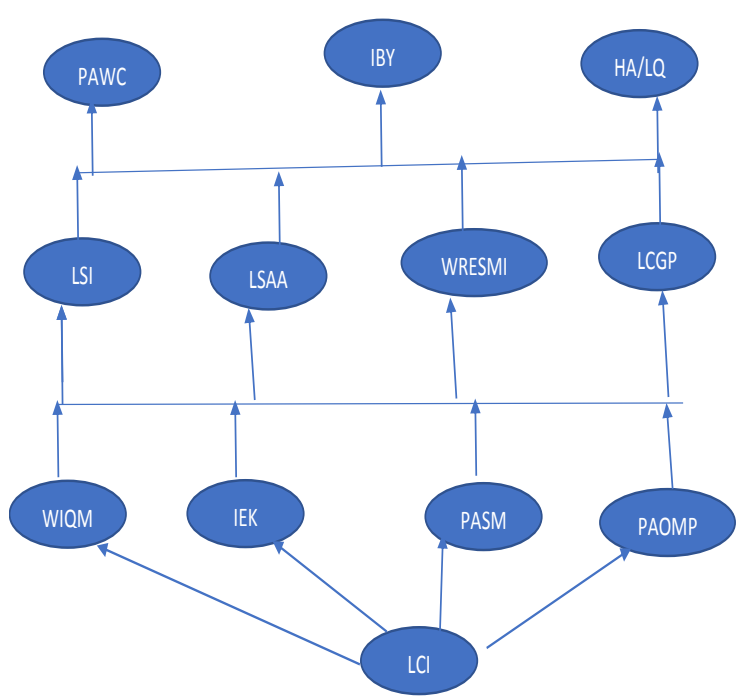

Fig 5 : ISM Diagraph

\section{ACKNOWLEDGEMENTS}

Author Remica Aggarwal is thankful to Prof. S,P Singh for disseminating the knowledge about ISM methodology which has helped her in writing this piece of work.

\section{APPENDICES}

A1: Common mistakes beginners make when writing content

- Failing To Create A Mind-Map: Source: focus.meisterlabs.com

Doesn't matter how many good ideas you have in your head, it'll all come to naught if you do not jot them down on a mind-map. These maps are essential as they help you paint a clearer picture of how you want your content take to shape before you even begin writing.

- $\quad$ Focussing On Quantity : [Source: wordpress.com] An eternal debate has been raging on for ages between Quality vs. Quantity. Although ruling out quantity is not at all recommended, doing so at the expense of quality is downright criminal. Quality content is what keeps the reader glued to your article. As a beginner, ensure that your blog posts/articles adhere to a quality standard before you commit to deliver a certain number of pieces.

- Not Paying Attention To SEO :[Source: www.hindisoch.com]

When you publish something, you obviously want people to read it. Search Engine Optimization helps you to reach out to your target audience. Incorporate relevant keywords and sentences in your article that you think potential readers will search for when they're browsing the internet. Forgetting the keywords, META content and tags are blatant mistakes that beginners tend to commit.

- Writing For Too Wide An Audience : [Source: partnerstitleco.com]

Writing, as an art form, is always targeted to a wide and diverse audience. But, when writing content for a brand/company, make sure you have a specific target group set in mind. Targeting a group of potential clients and buyers will help you not only set the right style and tone for your piece, but will also fetch you higher number of readers whom you can convert to buyers/subscribers. 
- $\quad$ Failing To Proofread : [Source: wikihow.com]

The gravest of the grave mistake that you can commit after writing content would be to not proofread your piece. Even an experienced writer commits mistakes like missing punctuation and silly typos. Which is why it is important to always proofread your articles before submitting them.

\section{A2: CONTENT WRITING OPPORTUNITIES IN INDIA}

Although the content writing challenges show a significant threat to Indian content industry, there's a multitude of opportunities too. some of them are as follows :

- Diversification in Work: Indian cyber space is growing fast to match up with international counterparts, and thus openings for content writers are also increasing at an alarming rate. More and more companies are looking to establish their business online, leaving a vast room for creativity.

- MNC Overrun: In India, MNCs are spreading like wildfire, and they're always modifying their appeal for new markets. Content is the most important part of this refinement. It can be in the form of re-writing advertisements, brochure content and even digital marketing. The more click bait your content is, the more are the chances to succeed.

- A Wider Range of Writers with Different Potentials: As most of the content writing is done through freelancing, there's a broader range of writers available in the industry. Content writing companies can look forward to the schools, colleges, and the potential public to find writers with varied expertise. For instance, creative writers, experienced and passionate retirees, or even educated stay-at-home moms.

- Freelancing Portals and Secure Payments: Online freelancing portals are increasing day by day, and thus, the opportunities for writers are increasing. These portals provide a platform where both the clients and freelancers can meet each other. Moreover, it's safe and easy to get payments from clients through freelancing portals.

- Digitization in India: With the emergence of digitization, more people are coming forward with the courage to open online businesses. With no investment required for physical offices and other expenses such as furniture, electricity, and water, etc., people are taking online businesses as a good option.

\section{REFERENCES}

[1] https://www.expertcontentwritersgroup.com/contentwriting-india-opportunities-challenges

[2] https://www.lexiconn.in/blog/5-common-mistakesbeginners-make-while-writing-content/

[3] Graphic Design \& Photography Bloggers: Lit Your Idea Bulb with these Content Inspirations Hunting Techniques : Clipping Path India, September 7, 2017 